\title{
PRICE NEGOTIATION AND COORDINATION IN OUTSOURCING SUPPLY CHAIN UNDER YIELD AND DEMAND UNCERTAINTIES
}

\author{
Zhiming $\mathrm{Chen}^{1} \odot$ And ChongPing $\mathrm{CHEN}^{2, *} \odot$
}

\begin{abstract}
This paper considers the issues of pricing, lot-sizing decisions and coordination in a supply chain consisting of one original equipment manufacturer (OEM) and one contract manufacturer (CM). A Bayesian game accounting for asymmetric information is established to optimize the CM's outsourcing price and the OEM's selling price. A Stackelberg game incorporating yield and demand uncertainties is subsequently modelled to optimize the CM's production quantity and the OEM's order quantity. Finally, a shortage penalty with surplus purchase contract is proposed to coordinate the supply chain. It is found that the optimal outsourcing price is either the lower limit or the stationary point of the common price domain, while the optimal selling price is the upper limit. Whether the CM adopts a conservative or an aggressive production strategy depends on the threshold of the outsourcing price. Moreover, the coordination contract offers great flexibility in parameter selection. By setting the order quantity, penalty price and surplus purchase price properly, the supply chain can realize a win-win situation.
\end{abstract}

Mathematics Subject Classification. 90B06.

Received April 20, 2021. Accepted November 14, 2021.

\section{INTRODUCTION}

Supply chains are currently facing great risks downstream. Due to rapid technological advances and fast consumer preference transitions, the demands in many industries, including electronics, automotive, fashion, and beverage, are changing more frequently than ever before. To mitigate demand volatility, firms may employ different flexible inventory strategies. One of the most common strategies for risk mitigation is outsourcing, wherein an original equipment manufacturer (OEM) conducts product design and then outsources the entire production to a contract manufacturer (CM). Many luxury brands such as Louis Vuitton, Coach, Prada and Burberry are reported to have established outsourcing cooperation networks with a variety of CMs around the world [23]. The past few decades have witnessed a boom in outsourcing. A market investigation of Statista, a famous German statistics portal, showed that the global outsourcing market amounted to $\$ 92.5$ billion in 2019. Taking advantage of the outsourcing strategy, firms can reap benefits by reducing costs, sustaining core competencies, obtaining desirable service levels, increasing flexibility and agility, and improving demand response speeds [6].

Keywords. Supply chain coordination, game theory, newsvendor, random yield, information asymmetry.

1 School of Credit Management, Guangdong University of Finance, Guangzhou 510521, P.R. China.

2 School of Politics and Public Administration, South China Normal University, Guangzhou 510006, P.R. China.

* Corresponding author: chongping_chen@163.com 
The outsourcing strategy decentralizes supply chains such that CMs may be located overseas. In the initial deal, the OEM and CM are usually unfamiliar with each other and thus do not know mutual price information [24]. In order to obtain extra benefits, they might not want to share their own reserve prices. Kostamis and Duenyas [21] stated that very few, if any, supply chains can function with all their members possessing the same amount of information. The presence of information asymmetry requires price negotiation to reach a deal. The ideal outsourcing price and selling price should be acceptable to each agent while generating as much profit as possible. Therefore, the pricing decision under unilateral information asymmetry is a great concern in the outsourcing business.

In the outsourcing mode, the number of products available for sale depends on the effective output of CM. A survey by Deloitte shows that $71 \%$ of 600 executives from global companies view supply risk as a critical factor impacting their strategic decisions [19]. Yield uncertainty is regarded as a major cause of supply risk. It is always impossible for a CM to produce the exact amount he plans for various reasons such as emergency events, quality problems, capacity constraints, labor shortages, and natural calamities. Yield uncertainty can lead to unexpected shortfalls in the required products. For instance, in early 2020, the outbreak of COVID-19 forced the Chinese government to severely restrict population mobility. Foxconn, a famous Chinese CM for Apple, could not recruit enough workers, leading to an approximately $10 \%$ decrease in iPhone production. Consequently, firms need to effectively manage yield uncertainty in their lot-sizing decisions to avoid such financial losses.

Our research questions are as follows: What are the optimal pricing strategies given unilateral information asymmetry? Facing yield and demand uncertainties, how should the OEM optimize his ordering strategy and the CM come up with responsive production strategy? Moreover, is there any coordination mechanism for improving the performance of decentralized supply chain?

In this paper, we consider one OEM (he) facing random demand that outsources his production to one CM (she) subject to random yield. Before trading, the CM's outsourcing price and the OEM's selling price are both private information. The optimal pricing policies for achieving an agreement are derived from a Bayesian game accounting for asymmetric information. Regarding the lot sizes, the OEM chooses how much to order based solely on his profit structure, and then the CM selects the production quantity best for her. In order to mitigate the negative impact of yield uncertainty, the CM can choose production quantity that may be larger than the order quantity, which is referred to as the voluntary compliance regime. The optimal lot-sizing decisions are derived from a Stackelberg game. Our model can be implemented as an expert system module in management information system to assist production planning and order allocation for the supply chain. With the benchmark of a centralized supply chain, we further propose a coordination contract called shortage penalty with surplus purchase, which is able to improve individual and overall profits.

The key contributions of this study lie in the following aspects. First, the information asymmetry we consider is bilateral instead of unilateral. Both the CM and the OEM own private price information. Compared with the traditional pricing decisions based on a Stackelberg game, we derive the optimal prices through a Bayesian game. Second, the lot-sizing decisions are implemented from the perspective of a voluntary compliance regime, which is more practical than a forced compliance regime. The game relationship reflecting the interaction between echelons is considered. That is, the upstream agent can choose the production quantity distinguished from the order quantity to mitigate the risk of uncertain yield, and the downstream agent can allocate orders considering the supply shortage problem. Third, we design a shortage penalty with surplus purchase contract to coordinate the supply chain under a complex situation wherein the upstream yield and downstream demand are both random. Numerical analyses provide insights into the contract's substantial flexibility in parameter selection. By setting the penalty price and surplus purchase price appropriately, the supply chain can achieve a win-win situation.

The remainder of this paper is organized as follows. Section 2 reviews relevant literature. Section 3 states the problem and models a Bayesian game for pricing decisions with information asymmetry and a Stackelberg game for lot-sizing decisions. Section 4 derives the centralized optimal solution as a benchmark and investigates the coordination mechanism of the shortage penalty with surplus purchase contract. Section 5 presents a numerical 
example and analyzes the managerial implications. Finally, Section 6 draws conclusions and suggests directions for future research.

\section{Literature REVIEW}

The first research stream related to this study is random yield, which has received widespread attention. For a complete review, we refer the reader to Yano and Lee [37] and Grosfeld-Nir and Gerchak [11]. Jung [18] compared offshore sourcing and onshore sourcing under yield and demand uncertainty. Hsieh and Lai [16] explored the order allocation for a capacity-constrained manufacturer, who sources from a stable-yield supplier producing standard-quality components and an unstable-yield supplier producing high-quality components. Du and Jiang [8] studied the backup or reliability improvement strategy to mitigate the risk of random yield using multi-agent modeling. $\mathrm{Xu}$ and $\mathrm{Lu}$ [35] investigated the impact of yield randomness on joint inventory and pricing decisions in procurement and in-house production. Given yield uncertainty, Wang et al. [32] examined the influence of potential spillover on the manufacturers' incentives to improve the suppliers' yield reliability. Xue et al. [36] explored supplier selection for a risk-averse manufacturer facing yield uncertainty using the mean-variance framework. Unlike the present work, these papers do not consider the issues of supply chain coordination and asymmetrical information.

The second relevant research stream is on pricing decisions in the supply chain. He and Zhao [15] derived the optimal pricing and ordering strategies for a three-stage supply chain with the supplier subject to random yield and the retailer subject to random demand. Giri et al. [10], and Giri and Bardhan [9] extended the model of He and Zhao [15] to consider the random yield of both the supplier and manufacturer. He [14] studied how firms sequentially make price and quantity decisions under yield and demand uncertainty. Li et al. [22] modified the model of He [14] to compare different decision sequences involving pricing and ordering. Serel [28] studied the optimal sourcing and pricing decisions for a newsvendor in the additive and multiplicative demand scenarios given uncertain supply capacity. Zabihi and Bafruei [38] considered the demand dependent on price and time, and derived the optimal price and discount time for perishable goods. Wu et al. [34] explored the optimal pricing and service policies for dual-channel reverse supply chain with online and offline recycling channels. Roy and Giri [27] studied the pricing and quality decisions in a three-stage supply chain with price and quality dependent demand. All these papers assume the price information to be common, that is, the price information of each agent is known to others. In contrast, we study pricing decisions under the assumption of asymmetrical price information.

Thus far, the research on operation decisions under asymmetrical price/cost information is not sufficient. For a complete review, we refer the reader to Vosooghidizaji et al. [31]. Nosoohi and Nookabadi [24] studied the order quantity under call option contract for a dominant manufacturer subject to the private information of supplier's cost. Kerkkamp et al. [20] coordinated the two-echelon supply chain including multiple retailer types with type-dependent default options under an asymmetrical cost structure. Given the information asymmetry on production cost and price-demand sensitivity, Chiu et al. [7] used a quantity discount contract to coordinate the supply chain under different leaderships. Xu et al. [35] investigated a manufacturer's optimal sourcing strategy when it faces a prime supplier with price setting power and an urgent supplier with private production cost information. Cao et al. [5] studied the problem of wholesale contract design in a supply chain where the retailer has private cost information and the manufacturer sells through the retailer as well as the direct channel. Pishchulov and Richter [26] performed an optimization analysis of the joint economic lot size model with asymmetric information of the buyer's cost. Zissis et al. [39] explored the effect of a quantity discount contract on the coordination between the manufacturer and retailer with private holding cost. Zissis et al. [40] extended the model of Zissis et al. [39] such that the quantity discount contract is implemented by a mediator instead of the manufacturer and the asymmetric information includes not only holding cost but also production cost. Table 1 summarizes the literature on inventory management under information asymmetry. Most of the papers consider private information of the cost structure, and assume unilateral information asymmetry, that is, there is information asymmetry in either the upstream agent or the downstream agent. In contrast, we 
TABLE 1. Studies on operation decisions under information asymmetry.

\begin{tabular}{|c|c|c|c|c|c|}
\hline Authors & $\begin{array}{l}\text { Private } \\
\text { information }\end{array}$ & $\begin{array}{l}\text { Asymmetric } \\
\text { type }\end{array}$ & Demand & Yield & $\begin{array}{l}\text { Decision } \\
\text { variable(s) }\end{array}$ \\
\hline $\begin{array}{l}\text { Nosoohi and } \\
\text { Nookabadi } \\
{[24]}\end{array}$ & $\begin{array}{l}\text { Upstream } \\
\text { cost }\end{array}$ & Unilateral & Random & Constant & Order quantity \\
\hline $\begin{array}{l}\text { Kerkkamp } \\
\text { et al. }[20]\end{array}$ & $\begin{array}{l}\text { Downstream } \\
\text { cost }\end{array}$ & Unilateral & Constant & Constant & Order quantity \\
\hline Chiu et al. [7] & $\begin{array}{l}\text { Upstream } \\
\text { cost } \\
\text { Downstream } \\
\text { demand }\end{array}$ & Unilateral & Random & Constant & Order quantity \\
\hline $\mathrm{Xu}$ et al. [35] & $\begin{array}{l}\text { Upstream } \\
\text { cost }\end{array}$ & Unilateral & Random & Constant & $\begin{array}{l}\text { Order quantity } \\
\text { Wholesale price }\end{array}$ \\
\hline Cao et al. [5] & $\begin{array}{l}\text { Downstream } \\
\text { cost }\end{array}$ & Unilateral & Constant & Constant & $\begin{array}{l}\text { Order quantity } \\
\text { Wholesale price }\end{array}$ \\
\hline $\begin{array}{l}\text { Pishchulov } \\
\text { and Richter } \\
{[26]}\end{array}$ & $\begin{array}{l}\text { Downstream } \\
\text { cost }\end{array}$ & Unilateral & Constant & Constant & Order quantity \\
\hline Zissis et al. [39] & $\begin{array}{l}\text { Downstream } \\
\text { cost }\end{array}$ & Unilateral & Constant & Constant & Order quantity \\
\hline Zissis et al. [40] & $\begin{array}{l}\text { Upstream } \\
\text { cost } \\
\text { Downstream } \\
\text { cost }\end{array}$ & Bilateral & Constant & Constant & Order quantity \\
\hline This study & $\begin{array}{l}\text { Upstream } \\
\text { price } \\
\text { Downstream } \\
\text { price }\end{array}$ & Bilateral & Random & Random & $\begin{array}{l}\text { Order/production } \\
\text { quantity } \\
\text { Outsourcing/selling } \\
\text { price }\end{array}$ \\
\hline
\end{tabular}

consider private information of the selling price, and allow information asymmetry (bilateral) to exist in both the upstream and downstream agents. Moreover, most of the papers focus on the lot-sizing decision but ignore the pricing decision, but we optimize both types of decisions. In addition, all these papers only consider the situation of constant/random demand, whereas we consider both random yield and random demand.

Finally, our research also falls within the literature on supply chain coordination. When each agent seeks local optimization without considering its impact on others, the performance of the supply chain decreases. Therefore, it is necessary to adopt coordination contract to achieve the global optimization. The classic contracts include revenue sharing [2], buy back [25], quantity discount [33], sales rebate [30], and side payment [26]. For a detailed description of them, we refer the reader to Cachon [3]. Different from the single contact, we use a composite contract called shortage penalty with surplus purchase. In complex situation, a composite contract is more flexible and powerful for coordination. The studies concerning supply chain coordination under both uncertain yield and demand, which are closely related to this paper, constitute a limited body of literature. Güler and Bilgiç [13] modeled a multi-sourcing assembly system under random yield and demand, and put forward a coordination contract composed of buy back, revenue sharing, and subsidy to the supplier with the worst yield. Based on the same setting, Güler [12] simplified the composite contract by arbitrarily excluding one of the three payment schemes. Tang and Kouvelis [29] proposed a pay-back-revenue-sharing contract for the supply chain comprising an unstable-yield supplier and a retailer facing random demand. Hu and Feng [17] derived the optimal supply and order quantities under the constraint of service requirement, and investigated the coordination based on revenue sharing contract. Cai et al. [4] analyzed the impacts of different commitment order contracts on the 
production decision of unstable-yield supplier and the performance of the supply chain with random demand. The above papers, except for Tang and Kouvelis [29], are restricted to a forced compliance regime assuming the equivalence between production quantity and order quantity. However, we consider a voluntary compliance regime where there is the interaction on lot sizes between echelons such that the production quantity may differ from the order quantity.

\section{MODEL DESCRIPTION}

We consider a decentralized supply chain consisting of one OEM (he) and one CM (she). Both make decisions based solely on their self-interests. The OEM decides to outsource his entire production to the CM, while the prices need to be determined via negotiation. The unit outsourcing price and unit production cost of the CM are $p_{1}$ and $c$, respectively $\left(p_{1} \geq c\right)$; and the unit selling price of the OEM is $p_{2}$. The OEM will make a deal with the $\mathrm{CM}$ only if $p_{2} \geq p_{1}$; otherwise, the negotiation breaks down, and the OEM searches for an alternative CM. The market demand is a random variable $y$ with probability density function (PDF) $f_{y}$ and cumulative distribution function $(\mathrm{CDF}) F_{y}$. Based on demand estimation, the OEM determines the order quantity $Q$. Upon receiving the order, the CM determines the production quantity $x$ according to her own reward structure, meaning that the production quantity may differ from the order quantity. Due to yield uncertainty, only a fraction $\alpha x$, where $\alpha$ is a random variable taking values in $(0,1]$ with $\operatorname{PDF} f_{\alpha}$ and $\operatorname{CDF} F_{\alpha}$, is delivered to the OEM. The amount $\alpha x$ can be considered as the effective output. We assume that there is no unit processing cost for the OEM or that the cost has been netted from $p_{2}$.

The profit function of the CM is

$$
\pi_{\mathrm{cm}}(x)=p_{1} \cdot \min (\alpha x, Q)-c x
$$

where the first term is the revenue from undertaking outsourcing, and the second term is the production cost. It is noteworthy that we consider a voluntary compliance regime wherein the CM produces according to not only the order from the OEM but also her own cost structure. The production quantity may differ from the order quantity.

Based on the newsvendor model, the profit function of the OEM is

$$
\pi_{\mathrm{oem}}(Q)=p_{2} \cdot \min (\alpha x, y, Q)-p_{1} \cdot \min (\alpha x, Q)
$$

where the first term is the revenue from sales, and the second term is the outsourcing cost.

\subsection{Price negotiation}

The selling price $p_{2}$ of the OEM is unknown to the CM before trade, but its range can be estimated through market research. We assume that $p_{2}$ falls in the interval $[l, u]$. Since the selling price is private information owned by the OEM, $p_{2}$ serves as a random variable for the CM with PDF $f_{p_{2}}$ and CDF $F_{p_{2}}$. Based on the interval of the selling price, the $\mathrm{CM}$ will determine the value of the outsourcing price, which can bring as much profit as possible and remain acceptable to the OEM. Meanwhile, the OEM does not know the unit outsourcing price of the CM, which also serves as a random variable $p_{1}$ for the OEM with PDF $f_{p_{1}}$ and CDF $F_{p_{1}}$. Given the price quote, the OEM should determine the selling price $p_{2}$ from the common interval $[l, u]$ to squeeze as much profit as possible. During the negotiation, both agents aim to maximize their own profits without knowing the exact prices of each other. This situation is essentially a Bayesian game with incomplete information. In the following analyses, we assume that the distributions of $p_{1}$ and $p_{2}$ are known to each agent.

For the CM, the bottom price is the unit $\operatorname{cost} c$, meaning that the CM is willing to undertake outsourcing only if $p_{1} \geq c$. However, the business is profitable for the OEM only if $p_{2} \geq p_{1}$. Otherwise, the negotiation collapses and the OEM tends to look for a lower-cost CM. Therefore, the optimal pricing strategy of the CM should maximize $p_{1}-\mathrm{c}$ with the constraint of $p_{2} \geq p_{1}$. The utility function of the CM is

$$
U_{\mathrm{cm}}\left(p_{1}\right)=\int_{p_{1}}^{u}\left(p_{1}-c\right) f_{p_{2}}\left(p_{2}\right) \mathrm{d} p_{2} .
$$


Proposition 3.1. If the distribution function of $p_{2}$ satisfies the condition $f_{p_{2}}^{\prime}\left(p_{1}\right)+\left(p_{1}-c\right) f_{p_{2}}^{\prime \prime}\left(p_{1}\right) \leq 0$, the optimal outsourcing price $p_{1}^{*}$ maximizing the utility of CM is solved by

$$
\begin{cases}1-F_{p_{2}}\left(p_{1}^{*}\right)-\left(p_{1}^{*}-c\right) f_{p_{2}}\left(p_{1}^{*}\right)=0, & \text { if } 1-(l-c) f_{p_{2}}(l)>0 \\ p_{1}^{*}=l, & \text { otherwise. }\end{cases}
$$

Proof. Computing the first derivative of equation (3.3) gives

$$
\frac{\mathrm{d} U_{\mathrm{cm}}\left(p_{1}\right)}{\mathrm{d} p_{1}}=1-F_{p_{2}}\left(p_{1}\right)-\left(p_{1}-c\right) f_{p_{2}}\left(p_{1}\right) .
$$

To identify values of $p_{1}$ that satisfy this first-order condition, let $R\left(p_{1}\right) \equiv \frac{\mathrm{d} U_{\mathrm{cm}}\left(p_{1}\right)}{\mathrm{d} p_{1}}$, and consider finding the zeros of $R\left(p_{1}\right)$ :

Additionally,

$$
\frac{\mathrm{d} R\left(p_{1}\right)}{\mathrm{d} p_{1}}=-f_{p_{2}}\left(p_{1}\right)\left[2+\left(p_{1}-c\right) \frac{f_{p_{2}}^{\prime}\left(p_{1}\right)}{f_{p_{2}}\left(p_{1}\right)}\right] \text {. }
$$

$$
\frac{\mathrm{d} R^{2}\left(p_{1}\right)}{\mathrm{d} p_{1}^{2}}=-\frac{f_{p_{2}}^{\prime}\left(p_{1}\right)}{f_{p_{2}}\left(p_{1}\right)} \cdot \frac{\mathrm{d} R\left(p_{1}\right)}{\mathrm{d} p_{1}}-\left[f_{p_{2}}^{\prime}\left(p_{1}\right)+\left(p_{1}-c\right) f_{p_{2}}^{\prime \prime}\left(p_{1}\right)\right]+\frac{\left(p_{1}-c\right)\left[f_{p_{2}}^{\prime}\left(p_{1}\right)\right]^{2}}{f_{p_{2}}\left(p_{1}\right)} .
$$

Then, we have

$$
\left.\frac{\mathrm{d} R^{2}\left(p_{1}\right)}{\mathrm{d} p_{1}^{2}}\right|_{\frac{\mathrm{d}_{R\left(p_{1}\right)}=0}{\mathrm{~d}_{p_{1}}}=0}=-\left[f_{p_{2}}^{\prime}\left(p_{1}\right)+\left(p_{1}-c\right) f_{p_{2}}^{\prime \prime}\left(p_{1}\right)\right]+\frac{\left(p_{1}-c\right)\left[f_{p_{2}}^{\prime}\left(p_{1}\right)\right]^{2}}{f_{p_{2}}\left(p_{1}\right)} .
$$

Note that $\frac{\left(p_{1}-c\right)\left[f_{p_{2}}^{\prime}\left(p_{1}\right)\right]^{2}}{f_{p_{2}}\left(p_{1}\right)}>0$. If the condition $f_{p_{2}}^{\prime}\left(p_{1}\right)+\left(p_{1}-c\right) f_{p_{2}}^{\prime \prime}\left(p_{1}\right) \leq 0$ holds, then it follows that $R\left(p_{1}\right)$ is either monotone or unimodal, implying that $R\left(p_{1}\right)=\frac{\mathrm{d} U_{\mathrm{cm}}\left(p_{1}\right)}{\mathrm{d} p_{1}}$ has at most two roots. Furthermore, since $R(u)=-\left(p_{1}-c\right) f_{p_{2}}\left(p_{1}\right)<0$, it indicates that there is at most one root $p_{1}^{*}$ satisfying $R\left(p_{1}^{*}\right)=0$. A sufficient condition for the root existence is $\left.\frac{\mathrm{d} U_{\mathrm{cm}}\left(p_{1}\right)}{\mathrm{d} p_{1}}\right|_{p_{1}=l}=1-(l-c) f_{p_{2}}(l)>0$. For $p_{1}<p_{1}^{*}, \frac{\mathrm{d} R\left(p_{1}\right)}{\mathrm{d} p_{1}}>0$. For $p_{1}>p_{1}^{*}$, $\frac{\mathrm{d} R\left(p_{1}\right)}{\mathrm{d} p_{1}}>0$. Thus, $p_{1}^{*}$ corresponds to the local maximum value of $U_{\mathrm{cm}}\left(p_{1}\right)$.

If $\left.\frac{\mathrm{d} U_{\mathrm{cm}}\left(p_{1}\right)}{\mathrm{d} p_{1}}\right|_{p_{1}=l}<0$, then the lower limit $p_{1}^{*}=l$ is the local maximum.

It is noteworthy that if the optimality condition $f_{p_{2}}^{\prime}\left(p_{1}\right)+\left(p_{1}-c\right) f_{p_{2}}^{\prime \prime}\left(p_{1}\right) \leq 0$ does not hold, then an exhaustive search over all values of $p_{1}$ in the region $[l, u]$ will determine $p_{1}^{*}$.

For the OEM, given the outsourcing price, his optimal pricing strategy should maximize $p_{2}-p_{1}$. The utility function of the OEM is:

$$
U_{\text {oem }}\left(p_{2}\right)=\int_{l}^{p_{2}}\left(p_{2}-p_{1}\right) f_{p_{1}}\left(p_{1}\right) \mathrm{d} p_{1} .
$$

Proposition 3.2. The utility function $U_{\mathrm{oem}}\left(p_{2}\right)$ monotonically increases with $p_{2}$, and there exists an optimal selling price $p_{2}^{*}=u$ that leads to the maximum utility.

Proof. Because the derivative of $U_{\mathrm{oem}}\left(p_{2}\right)$ satisfies

$$
\frac{\mathrm{d} U_{\text {oem }}\left(p_{2}\right)}{\mathrm{d} p_{2}}=F_{p_{1}}\left(p_{2}\right)>0
$$

the utility function is a monotonically increasing function of $p_{2}$. As $p_{2}$ reaches its upper limit, the utility function is maximized. 
The optimal unit outsourcing price $p_{1}^{*}$ can be solved by equation (3.4), which is the highest price pursued by the CM without harming the interest of the OEM. Once the CM charges higher than $p_{1}^{*}$, the OEM barely makes a profit; thus, it is unlikely to conclude the transaction. According to Proposition 3.2, the optimal unit selling price $p_{2}^{*}$ equals the upper limit of the common price interval. In other words, within the acceptance price range of consumers, the OEM will seek the highest selling price. Hence, $\left(p_{1}^{*}, p_{2}^{*}\right)$ are the equilibrium prices of negotiation that simultaneously maximize the utility functions of the OEM and CM.

\subsection{Decentralized decisions}

After confirming the prices, the OEM determines the order quantity $Q$ in the outsourcing, and then the CM determines the production quantity $x$. The decision process under decentralization forms a Stackelberg game, wherein the OEM serves as the leader that first chooses the order quantity and the CM serves as the follower that subsequently selects the production quantity. The approach of backward induction is used to achieve the Stackelberg equilibrium, with the optimal production quantity and the optimal order quantity solved sequentially.

Computing the expectation of equation (3.1) leads to the CM's expected profit function

$$
\begin{aligned}
\Pi_{\mathrm{cm}}(x) & =p_{1}^{*} \cdot E[\min (\alpha x, Q)]-c x \\
& =p_{1}^{*} x \int_{0}^{\frac{Q}{x}} \alpha f_{\alpha}(\alpha) \mathrm{d} \alpha+p_{1}^{*} Q\left[1-F_{\alpha}\left(\frac{Q}{x}\right)\right]-c x .
\end{aligned}
$$

Proposition 3.3. The CM's expected profit $\Pi_{\mathrm{cm}}$ is concave in $x$, and the optimal production quantity $x^{*}$ maximizing $\Pi_{\mathrm{cm}}$ is solved by

$$
\frac{\partial \Pi_{\mathrm{cm}}}{\partial x}=p_{1}^{*} \int_{0}^{\frac{Q}{x}} \alpha f_{\alpha}(\alpha) \mathrm{d} \alpha-c=0 .
$$

It is easy to show that $\frac{\partial^{2} \Pi_{\mathrm{cm}}}{\partial x^{2}}=-p_{1}^{*} \frac{Q^{2}}{x^{3}} f_{\alpha}\left(\frac{Q}{x}\right)<0$, thus $\Pi_{\mathrm{cm}}$ is a concave function. Solving the first-order condition of equation (3.6) leads to equation (3.7).

Computing the expectation of equation (3.2) leads to the OEM's expected profit function

$$
\begin{aligned}
\Pi_{\mathrm{oem}}(Q)= & p_{2}^{*} \cdot E[\min (\alpha x, y, Q)]-p_{1}^{*} \cdot E[\min (\alpha x, Q)] \\
= & p_{2}^{*}\left[\int_{\alpha x}^{+\infty} \int_{0}^{\frac{Q}{x}} \alpha x f_{\alpha}(\alpha) \mathrm{d} \alpha f_{y}(y) \mathrm{d} y+\int_{0}^{Q} \int_{\frac{y}{x}}^{1} y f_{\alpha}(\alpha) \mathrm{d} \alpha f_{y}(y) \mathrm{d} y\right. \\
& \left.+\int_{Q}^{+\infty} \int_{\frac{Q}{x}}^{1} Q f_{\alpha}(\alpha) \mathrm{d} \alpha f_{y}(y) \mathrm{d} y\right]-p_{1}^{*}\left\{x \int_{0}^{\frac{Q}{x}} \alpha f_{\alpha}(\alpha) \mathrm{d} \alpha+Q\left[1-F_{\alpha}\left(\frac{Q}{x}\right)\right]\right\} .
\end{aligned}
$$

Proposition 3.4. The OEM's expected profit $\Pi_{\mathrm{oem}}$ is concave in $Q$, and there exists an optimal order quantity $Q^{*}$ maximizing $\Pi_{\mathrm{oem}}$.

Proof. The first-order condition of equation (3.8) is

$$
\left.\frac{\partial \Pi_{\mathrm{oem}}}{\partial Q}\right|_{Q=Q^{*}}=\left[1-F_{\alpha}\left(\frac{Q^{*}}{x}\right)\right]\left\{p_{2}^{*}\left[1-F_{y}\left(Q^{*}\right)\right]-p_{1}^{*}\right\}=0 .
$$

Then, when $Q>Q^{*}$,

$$
\left[1-F_{\alpha}\left(\frac{Q^{*}}{x}\right)\right]\left\{p_{2}^{*}\left[1-F_{y}\left(Q^{*}\right)\right]-p_{1}^{*}\right\}<0
$$

Then, when $Q<Q^{*}$,

$$
\left[1-F_{\alpha}\left(\frac{Q^{*}}{x}\right)\right]\left\{p_{2}^{*}\left[1-F_{y}\left(Q^{*}\right)\right]-p_{1}^{*}\right\}>0 .
$$

Therefore, $\Pi_{\text {oem }}$ is concave in $Q$, with the maximum value achieved at $Q=Q^{*}$. 
The equilibrium production and order quantities $\left(x^{*}, Q^{*}\right)$ can be solved by combining equations (3.7) and (3.9), which enables profit maximization for both agents in the game. Note that the CM is independent of the OEM and considers her own cost structure for decision making. Thus, the production quantity may differ from the order quantity. Let $z=Q / x$. Then, equation (3.7) transforms to a function of $z$, indicating that the first-order condition depends on the ratio of $Q$ to $x$ rather than on each variable. Hence, the optimal production quantity of the CM is equal to the order quantity multiplied by a factor $1 / z$ determined by equation (3.7). Moreover, since the integral upper limit of equation (3.7) is the largest value of integral variable $\alpha, Q / x$ should not be larger than 1, indicating that the optimal production quantity must be greater than or equal to the order size. If $\left.\frac{\partial \Pi_{\mathrm{cm}}}{\partial x}\right|_{x=Q}=p_{1}^{*} E(\alpha)-c \leq 0, \Pi_{\mathrm{cm}}$ is a decreasing function of $x$, then it can be concluded that the optimal production quantity is in accordance with the order size. If $\left.\frac{\partial \Pi_{\mathrm{cm}}}{\partial x}\right|_{x=Q}=p_{1}^{*} E(\alpha)-c>0, \Pi_{\mathrm{cm}}$ first increases and then decreases with $x$, then it can be inferred that the optimal production quantity exceeds the order size. Therefore, $c / E(\alpha)$ is the threshold of the outsourcing price, which determines whether the CM should adopt a conservative or aggressive production strategy.

\section{Supply CHAin COORDination}

\subsection{Optimal lot sizes under centralization}

In the scenario of centralization, the OEM and CM operate as a system to make collaborative decisions for maximizing the profit of the whole supply chain. However, given the independence of each agent in reality, they usually focus on the maximization of their own profits. This double marginalization problem results in a deviation of decentralized lot sizes from the global optima.

As an ideal objective function, the profit of the centralized supply chain is

$$
\pi_{\mathrm{sc}}(x)=p_{2}^{*} \cdot \min (\alpha x, y)-c x .
$$

Its expectation is

$$
\Pi_{\mathrm{sc}}(x)=p_{2}^{*}\left[\int_{0}^{1} \int_{\alpha x}^{+\infty} \alpha x f_{y}(y) \mathrm{d} y f_{\alpha}(\alpha) \mathrm{d} \alpha+\int_{0}^{1} \int_{0}^{\alpha x} y f_{y}(y) \mathrm{d} y f_{\alpha}(\alpha) \mathrm{d} \alpha\right]-c x .
$$

Given the concavity of linear function, $\alpha x$ as a linear function of $x$ is concave. Since the concavity is preserved under minimum and expectation operations [1], $\Pi_{\mathrm{sc}}$ is concave in $x$ and has the maximum value. Note that the variable $Q$ is absent in equation (4.1) because the CM and OEM perform as a whole under centralization. Without the ordering process from the OEM, the CM directly decides the production quantity based on the demand.

The global optimal production quantity $x^{* *}$ maximizing $\Pi_{\mathrm{sc}}$ under centralization is derived from the firstorder condition

$$
\left.\frac{\partial \Pi_{\mathrm{sc}}}{\partial x}\right|_{x=x^{* *}}=p_{2}^{*} \int_{0}^{1}\left[1-F_{y}\left(\alpha x^{* *}\right)\right] \alpha f_{\alpha}(\alpha) \mathrm{d} \alpha-c=0 .
$$

As for the decentralized supply chain, the total profit equals to the sum of equations (3.1) and (3.2),

$$
\Pi_{\mathrm{sc}}^{\prime}(Q, x)=p_{2}^{*} E[\min (\alpha x, Q, y)]-c x .
$$

Because $\min (\alpha x, Q, y)=\min [\min (\alpha x, Q), y], \min (\alpha x, Q) \leq \alpha x$, we have $\min [\min (\alpha x, Q), y] \leq \min (\alpha x, y)$, that is, the decentralized total profit is always less than or equal to the centralized profit. Based on equation (4.3), we calculate the first derivative with respect to $Q$ :

$$
\frac{\partial \Pi_{\mathrm{sc}}^{\prime}}{\partial Q}=p_{2}^{*}\left[1-F_{y}(Q)\right]\left[1-F_{\alpha}\left(\frac{Q}{x}\right)\right]=0 .
$$


Since $F_{y}(Q)<1$, we have $1-F_{\alpha}\left(\frac{Q}{x}\right)=0 \Rightarrow x=Q$, and accordingly

$$
\min (\alpha x, Q, y)=\min (\alpha x, x, y)=\min (\alpha x, y) .
$$

Therefore, $x=Q$ is a sufficient condition for coordinating the decentralized supply chain. In the following section, a composite contract to achieve coordination under the condition of $x \neq Q$ will be proposed.

\subsection{Shortage penalty with surplus purchase contract}

Given the uncertainties in both demand and yield, the coordination mechanism aims to reduce the potential loss stemming from stochastic risk. On the one hand, due to the uncertain yield of the CM, the OEM is likely to suffer a shortage problem that results in opportunity loss. On the other hand, if the outsourcing price is attractive, the CM tends to produce more than the quantity ordered. Such production strategy may result in an overstock problem, which places extra burdens on the CM. In order to improve the performance of both agents, we propose a composite contract called shortage penalty with surplus purchase. Since the CM plays the role of the follower, the contract is set by the OEM with details as follows:

(1) When the effective output is less than the order quantity, the OEM faces the shortage problem. This situation is double-edged due to the demand uncertainty. If the demand is lower than the order quantity, the OEM indirectly benefits from the shortage, which reduces the leftover inventory as well as the holding cost. If the demand exceeds the order quantity, the OEM suffers indirect losses from the shortage, because of missing the opportunity to sell more products and the associated profit decrease. In the latter situation, the CM should be punished for her insufficient output. Provided the unit penalty price $p_{0}$, the total penalty paid to the OEM is $p_{0} \cdot[Q-\alpha x]^{+}$.

(2) When the effective output is larger than the order quantity, the CM faces the overstock problem. As the CM does not possess her own sales channel, the surplus products cannot be transformed into revenue. In contrast, facing uncertain demand, the OEM needs to maintain more stock for a rainy day. Hence, the OEM can purchase the surplus products from the CM with a price cheaper than $p_{1}^{*}$. This way is efficient to remove the overstock of the CM and to reduce the shortage risk of the OEM. Let $m$ be the unit surplus purchase price. Then, the total subsidy acquired by the CM is $m \cdot[\alpha x-Q]^{+}$.

After introducing the coordination contract, the actual product quantity received by the OEM is no longer equal to the order quantity $Q$. Instead, it equals the CM's effective output $\alpha x$. Accordingly, the new profit function of the OEM is modified as

$$
\pi_{\mathrm{oem}}^{\prime}=p_{2}^{*} \cdot \min (\alpha x, y)-p_{1}^{*} \cdot \min (\alpha x, Q)-m \cdot[\alpha x-Q]^{+}+p_{0} \cdot[Q-\alpha x]^{+} \cdot \min \left\{[D-Q]^{+}, 1\right\}
$$

where $[x]^{+}=\max \{0, x\}$. The third term represents the cost of purchasing surplus products, and the fourth term denotes the shortage penalty placed on the CM only if the demand exceeds the order quantity.

The new profit function of the CM is modified as

$$
\pi_{\mathrm{cm}}^{\prime}=p_{1}^{*} \cdot \min (\alpha x, Q)-c x-p_{0} \cdot[Q-\alpha x]^{+} \cdot \min \left\{[D-Q]^{+}, 1\right\}+m \cdot[\alpha x-Q]^{+} .
$$

From equations (4.4) and (4.5), the shortage penalty with surplus purchase contract leads to a transfer payment within the supply chain. The sum of both agents' profits under decentralization has the same functional form as that of the global profit under centralization: $\pi_{\mathrm{oem}}^{\prime}+\pi_{\mathrm{cm}}^{\prime}=\pi_{\mathrm{sc}}$. Thus, the supply chain can be coordinated if the optimal production quantity under decentralization is equal to that under centralization.

Computing the expectation of equation (4.5) gives 


$$
\begin{aligned}
\Pi_{\mathrm{cm}}^{\prime}= & p_{1}^{*} x \int_{0}^{\frac{Q}{x}} \alpha f_{\alpha}(\alpha) \mathrm{d} \alpha+p_{1}^{*} Q\left[1-F_{\alpha}\left(\frac{Q}{x}\right)\right]-c x-p_{0} \int_{Q}^{+\infty} \int_{0}^{\frac{Q}{x}}(Q-\alpha x) f_{\alpha}(\alpha) \mathrm{d} \alpha f_{y}(y) \mathrm{d} y \\
& +m \int_{\frac{Q}{x}}^{1}(\alpha x-Q) f_{\alpha}(\alpha) \mathrm{d} \alpha .
\end{aligned}
$$

The first-order condition of $\Pi_{\mathrm{cm}}^{\prime}$ is computed as

$$
\frac{\partial \Pi_{\mathrm{cm}}^{\prime}}{\partial x}=p_{1}^{*} \int_{0}^{\frac{Q}{x}} \alpha f_{\alpha}(\alpha) \mathrm{d} \alpha-c+p_{0}\left[1-F_{y}(Q)\right] \int_{0}^{\frac{Q}{x}} \alpha f_{\alpha}(\alpha) \mathrm{d} \alpha+m \int_{\frac{Q}{x}}^{1} \alpha f_{\alpha}(\alpha) \mathrm{d} \alpha=0 .
$$

Given $x$, both equations (4.6) and (4.7) are the functions of variables $p_{0}, m$, and $Q$ as

$$
\Pi_{\mathrm{cm}}^{\prime}=H\left(Q, p_{0}, m\right), \frac{\partial \Pi_{\mathrm{cm}}^{\prime}}{\partial x}=G\left(Q, p_{0}, m\right) .
$$

Now we illustrate how the contract coordinates the supply chain. As the leader of the supply chain, the OEM can first select proper $(Q, m)$ such that the CM chooses the global optimum as her optimal production quantity under decentralization, that is, $x^{* *}$ satisfies the first-order condition equation (4.7). Then $p$ is appropriately chosen to ensure that the CM's profit equation (4.6) is greater than or equal to that before coordination. Specifically, the parameters of the contract should satisfy the formulas

$$
\left\{\begin{array}{l}
G\left(Q, p_{0}, m\right)_{\mid x=x^{* *}}=0 \\
H\left(Q, p_{0}, m\right)_{\mid x=x^{* *}} \geq \Pi_{\mathrm{cm}}^{*}
\end{array}\right.
$$

where $\Pi_{\mathrm{cm}}^{*}$ represents the maximum profit of the CM before coordination. Since there are more variables than constraints in equation (4.8), the contract offers great flexibility to the OEM in choosing its optimal parameters. According to equation (4.7), $Q$ can be written as a function of $\left(p_{0}, m\right)$. After substituting $Q\left(p_{0}, m\right)$ into equation (4.6), the profit function of the CM depends only on $\left(p_{0}, m\right)$ given $x=x^{* *}$. Hence, the OEM can arbitrarily control the profit of the CM by manipulating the values of $\left(p_{0}, m\right)$. Moreover, for any given CM's profit, the OEM can adjust the order quantity $Q$ to guarantee the values of $\left(p_{0}, m\right)$ within a reasonable range. In a win-win situation, the profits of both agents can be increased by implementing the contract.

\section{Computational Results}

\subsection{Numerical examples}

This section presents a series of numerical examples to examine the results of the previous analysis. Specifically, we illustrate how to calculate the optimal prices, lot sizes and profits for the agents, as well as the parameters of the coordination contract. Then, we conduct sensitivity analysis on the ordering and production strategies, illustrate how the contract influences the agents' profits, and show the flexibility of the contract in parameter selection.

Consider the case of one OEM outsourcing his production to one CM. Due to information asymmetry, the CM's outsourcing price $p_{1}$ is unknown to the OEM, and the OEM's selling price $p_{2}$ is unknown to the CM. According to market research, $p_{1}$ and $p_{2}$ can be estimated to follow a uniform distribution over [15, 36]. The $\mathrm{CM}$ has unit production $\operatorname{costs} c=10$ and uniformly distributed yield uncertainty $\alpha \sim U(0,1]$. The OEM faces random demand with a normal distribution $y \sim N\left(100,50^{2}\right)$.

We can derive the optimal outsourcing price $p_{1}^{*}=23$ from equation (3.4), and the optimal selling price $p_{2}^{*}=36$ from Proposition 3.2. Under decentralization, according to equations (3.7) and (3.9), we can obtain the optimal production quantity $x^{*}=89$ and the optimal order quantity $Q^{*}=83$, and substitute them into equations (3.6) and (3.8) to obtain the profits $\Pi_{\mathrm{cm}}=128.9$ and $\Pi_{\mathrm{oem}}=421.1$. Under centralization, the optimal production 


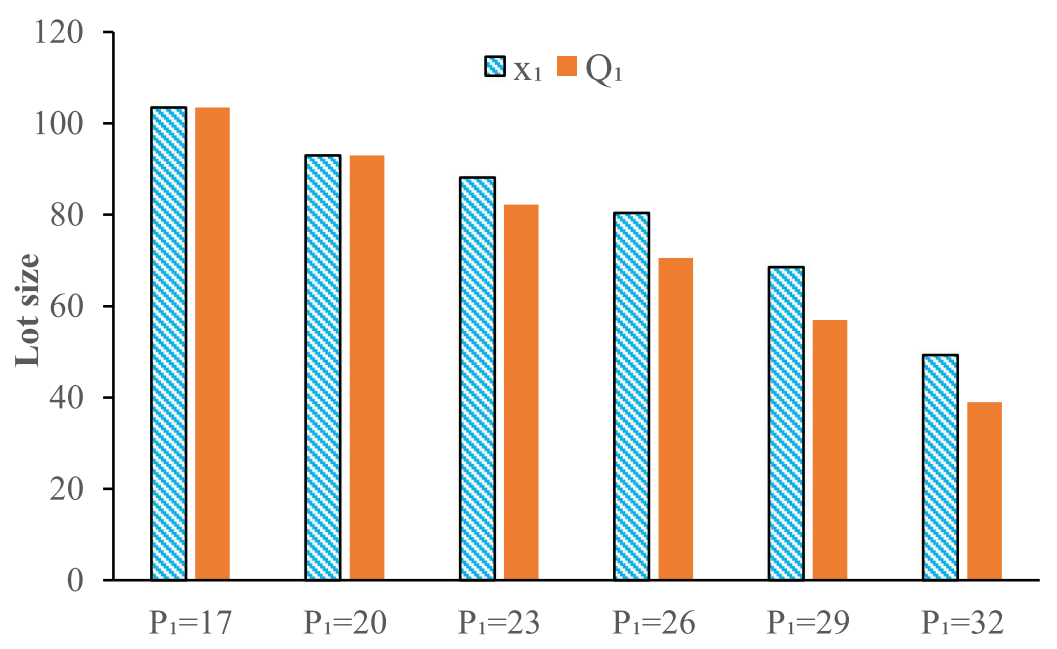

FiguRE 1. Lot sizes under different outsourcing prices.

quantity $x^{* *}=136$ and the associated total profit of the supply chain $\Pi_{\mathrm{sc}}=647.9$ are solved by equations (4.2) and (4.1), respectively. The results verify that the decentralized supply chain possesses lower production quantity than the centralized supply chain and thus suffers from a profit reduction. Based on equation (4.8), where the contract parameters can be set as unit penalty price $p_{0}=1.29$, unit surplus purchase price $m=5.45$ and order quantity $Q=123$, the CM's optimal production quantity can be increased to 136 . Consequently, the profits of the OEM and $\mathrm{CM}$ are respectively enhanced to $\Pi_{\mathrm{oem}}^{\prime}=477.9$ and $\Pi_{\mathrm{cm}}^{\prime}=170$, with their sum equal to the centralized maximum profit. This shows that the shortage penalty with surplus purchase contract can coordinate the supply chain and improve the overall profit as well as individual profits.

The influence of the outsourcing price on lot sizes is depicted in Figure 1. It can be seen that $p_{1}=20$ is the watershed of the CM's production strategy. If the outsourcing price is lower than this value, the CM tends to employ a conservative strategy, wherein production is conducted strictly in accordance with the order. Since the revenue cannot make up for the cost given low outsourcing price, the $\mathrm{CM}$ is unwilling to produce more to expand her effective output. Otherwise, the CM is motivated to overproduce to reduce the gap between the effective output and the order. Moreover, the amount of overproduction (production quantity minus order quantity) increases as the outsourcing price rises due to the attractive margin. However, a high outsourcing price means a low margin for the OEM, resulting in order cuts and thus a low production scale.

The impact of contract parameters on the agents' profits is shown in Table 2. Given the order quantity, there is a general trend that the profit of the CM increases with $m$ and decreases with $p_{0}$. In contrast, the profit of the OEM decreases with $m$ and increases with $p_{0}$. It is intuitive that the CM subject to yield uncertainty can benefit from surplus purchase but lose from shortage penalty. The transfer payment to the OEM is the opposite, resulting in a reversed trend between contract parameters and the OEM's profit. When the CM's profit drops below 96 , the surplus purchase price is less than zero, meaning that the CM needs to pay money for selling the surplus products. When the CM's profit rises beyond 194, the penalty price is less than zero, meaning that the OEM needs to subsidize the shortage. Therefore, the CM's coordinated profit $\Pi_{\mathrm{cm}}^{\prime}$ should not be set too large or too small. Otherwise, the values of contract parameters become negative, which is against the principle of the contract. Note that the CM's maximum profit before coordination is 128.9 . When $m<2.46$ and $p_{0}>3.47$, $\Pi_{\mathrm{cm}}^{\prime}$ is lower than 128.9, indicating that the OEM is better off at the expense of the CM's profit. Although all the values of $\left(p_{0}, m\right)$ in Table 2 can coordinate the supply chain, only parts of them $(2.46 \leq m \leq 7.2$, $\left.0.01 \leq p_{0} \leq 3.47\right)$ can realize a win-win situation. A surplus purchase price that is too small or a shortage penalty price that is too large will prevent the CM from joining the coordination scheme. These results indicate that the contract parameters should be set within a reasonable range. 
TABle 2. Production quantities and profits under different contract parameters given $Q=123$.

\begin{tabular}{lllll}
\hline \hline$m$ & $P_{0}$ & $x$ & $\Pi_{\mathrm{oem}}^{\prime}$ & $\Pi_{\mathrm{cm}}^{\prime}$ \\
\hline 0.07 & 5.22 & 136 & 551.9 & 96 \\
0.80 & 4.69 & 136 & 541.9 & 106.0 \\
1.52 & 4.12 & 136 & 531.9 & 116.0 \\
2.25 & 3.62 & 136 & 521.9 & 126.0 \\
2.46 & 3.47 & 136 & 519.0 & 128.9 \\
2.98 & 3.09 & 136 & 511.9 & 136.0 \\
3.70 & 2.56 & 136 & 501.9 & 146.0 \\
4.43 & 2.03 & 136 & 491.9 & 156.0 \\
5.16 & 1.50 & 136 & 481.9 & 166.0 \\
5.88 & 0.97 & 136 & 471.9 & 176.0 \\
6.61 & 0.44 & 136 & 461.9 & 186.0 \\
7.20 & 0.01 & 136 & 453.9 & 194.0 \\
\hline
\end{tabular}

TABLE 3. Contract parameters under different $Q$ given $\Pi_{\mathrm{cm}}^{\prime}=160$.

\begin{tabular}{lllll}
\hline \hline$Q$ & $m$ & $P_{0}$ & $x$ & $\Pi_{\text {oem }}^{\prime}$ \\
\hline 123 & 4.72 & 1.82 & 136 & 487.9 \\
113 & 12.22 & 1.24 & 136 & 487.9 \\
103 & 15.49 & 0.75 & 136 & 487.9 \\
93 & 17.23 & 0.27 & 136 & 487.9 \\
83 & 18.32 & -0.27 & 136 & 487.9 \\
73 & 19.06 & -0.97 & 136 & 487.9 \\
\hline
\end{tabular}

As mentioned in Section 4.2, there is one degree of freedom in equation (4.8), which offers great flexibility in parameter selection for the OEM. In other words, given a specific profit of CM, the OEM can obtain reasonable values of $\left(p_{0}, m\right)$ by choosing $Q$. To ensure the feasibility of the contract, the parameters should satisfy $0<$ $m \leq p_{1}^{*}$ and $0<p_{0} \leq p_{2}^{*}$. In other words, the surplus purchase price paid for the CM should not be beyond the outsourcing price, and the penalty price charged by the OEM should not be beyond the selling price. Provided that the CM's coordinated profit is 160 , various values of $\left(p_{0}, m\right)$ can be obtained with different order quantities, as shown in Table 3. It is found that $m$ decreases with $Q$ while $p_{0}$ increases with $Q$. The reason is that when the CM improves her production quantity to the global optimum, she will suffer a higher risk of overstock from a lower order quantity, and thus require a greater price allowance for surplus products. Since understock risk is unlikely to occur in such condition, she should not pay a high penalty price. It is noteworthy that the condition $Q \leq 83$ produces a negative penalty price, which is unrealistic. Thus, the order quantity should be set greater than 83 .

\subsection{Managerial implications}

To help decision-makers better manage their supply chains, we draw managerial insights from previous numerical examples. There is a threshold outsourcing price that plays a critical role in determining the production strategy of the CM. Given an outsourcing price larger than the threshold, the CM is motivated to overproduce to narrow the gap between effective output and order quantity. Otherwise, due to the low gross margin, she is inclined to adopt a conservative production quantity that is strictly equal to the order. Although a low outsourcing price reduces the positivity of production, it attracts the OEM to allocate more orders, which in turn increases the production scale. 
After introducing the shortage penalty with surplus purchase contract, the CM's production quantity depends on not only the OEM's order quantity, but also the penalty price and surplus purchase price. There are various contract parameter schemes to induce supply chain coordination. Increasing the surplus purchase price or lowering the penalty price can lead to profit improvement for the CM, and opposite changes in the two parameters can result in profit improvement for the OEM. In order to achieve a win-win situation and ensure feasible implementation, the contract parameters should be restricted within a reasonable range. In coordination, a smaller order quantity is usually associated with a larger surplus purchase price and a smaller penalty price. Such relationships among contract parameters can be explained by the fact that given the global optimal production quantity, the CM suffers a higher overstock risk from a lower order quantity, and thus requires a greater price allowance for surplus products. Because understock risk is unlikely to occur in such condition, the penalty price should not be high.

\section{Conclusions}

In this work, we investigate the issue of the coordination of a supply chain comprising one OEM and one CM. The price negotiation model is developed based on a Bayesian game to address asymmetric price information during trade. Modified newsvendor models accounting for the OEM's uncertain demand and CM's uncertain yield are subsequently constructed to derive the optimal lot sizes. In order to improve the total performance of the supply chain, we propose a shortage penalty with surplus purchase contract.

The main findings of this paper are as follows: (1) In the price negotiation wherein both agents do not know the prices of each other, there exist Bayesian equilibrium prices for reaching a deal. In equilibrium, due to the limitation of the selling price, the outsourcing price of the CM is set as either the lower limit or the stationary point of the common price interval. In contrast, since higher price within the acceptance scope of customers leads to enhanced profit, the selling price of the OEM is set as the largest common price. (2) There is a threshold of the outsourcing price that determines whether the CM should adopt a conservative or an aggressive production strategy. An attractive outsourcing price larger than the threshold stimulates the CM to produce more than the quantity ordered, reducing the difference between the effective output and the order. Otherwise, the CM tends to produce in accordance with the order. (3) The supply chain can be coordinated by a shortage penalty with surplus purchase contract. If the effective output is larger than the order quantity, the OEM purchases the surplus products from the $\mathrm{CM}$ at a cheap price, aiming to reduce his own shortage risk and consume the CM's overstock. Otherwise, the OEM punishes the CM for the shortage to alleviate the opportunity loss. The advantage of this contract is the great flexibility in parameter selection and profit allocation. By choosing the contract parameters properly, a win-win situation can be achieved.

To restrict the analysis to the area of interest, we ignore the salvage value of unsold items and the goodwill cost for unmet demand. Future work can incorporate them into the newsvendor model to conduct a comprehensive investigation. In addition, we assume unlimited capacity for the CM. Whether the overproduction strategy holds with the capacity constraint needs further examination. Moreover, the number of suppliers considered in this paper is only one. If the OEM adopts a multi-sourcing strategy, the problems of supplier selection and order allocation are worthwhile research directions.

Acknowledgements. This research is supported by National Natural Science Foundation of China [No. 71802057]; Natural Science Foundation of Guangdong Province [No. 2018A030313424], [No. 2020A1515111044], [No. 2021A1515012211]; the 13th Five-Year Plan of Philosophy and Social Science of Guangdong Province [No.GD20YGL05].

\section{REFERENCES}

[1] D.P. Bertsekas, A. Nedic and A.E. Ozdaglar, Convex Analysis and Optimization. Athena Scientific (2003).

[2] G.P. Cachon and M.A. Lariviere, Supply chain coordination with revenue-sharing contracts: strengths and limitations. Manage. Sci. 51 (2005) 30-44.

[3] G.P. Cachon, S. Graves and T. Kok, Supply chain coordination with contracts. In: Handbooks in Operations Research and Management Science: Supply Chain Management. North Holland, Amsterdam (2003) 229-340. 
[4] J. Cai, X. Hu, F. Jiang, Q. Zhou, X. Zhang and L. Xuan, Optimal input quantity decisions considering commitment order contracts under yield uncertainty. Int. J. Prod. Econ. 216 (2019) 398-412.

[5] E. Cao, Y.J. Ma, C. Wan and M.Y. Lai, Contracting with asymmetric cost information in a dual-channel supply chain. Oper. Res. Lett. 41 (2013) 410-414.

[6] K. Chen, H. Zhao and T. Xiao, Outsourcing contracts and ordering decisions of a supply chain under multi-dimensional uncertainties. Comput. Ind. Eng. 130 (2019) 127-141.

[7] C.H. Chiu, T.M. Choi, X. Li and C. Yiu, Coordinating supply chains with a general price-dependent demand function: impacts of channel leadership and information asymmetry. IEEE Trans. Eng. Manage. 63 (2016) 390-403.

[8] H. Du and Y. Jiang, Backup or reliability improvement strategy for a manufacturer facing heterogeneous consumers in a dynamic supply chain. IEEE Access. 7 (2019) 50419-50430.

[9] B.C. Giri and S. Bardhan, Sub-supply chain coordination in a three-layer chain under demand uncertainty and random yield in production. Int. J. Prod. Econ. 191 (2017) 66-73.

[10] B.C. Giri, S. Bardhan and T. Maiti, Coordinating a three-layer supply chain with uncertain demand and random yield. Int. J. Prod. Res. 54 (2016) 2499-2518.

[11] A. Grosfeld-Nir and Y. Gerchak, Multiple lot sizing in production to order with random yields: review of recent advances. Ann. Oper. Res. 126 (2004) 43-69.

[12] M.G. Güler, Coordinating decentralised assembly systems with random yield and random demand. Int. J. Prod. Res. 53 (2015) 886-896.

[13] M.G. Güler and T. Bilgiç, On coordinating an assembly system under random yield and random demand. Eur. J. Oper. Res. 196 (2009) 342-350.

[14] Y. He, Sequential price and quantity decisions under supply and demand risks. Int. J. Prod. Econ. 141 (2013) $541-551$.

[15] Y. He and X. Zhao, Coordination in multi-echelon supply chain under supply and demand uncertainty. Int. J. Prod. Econ. 139 (2012) 106-115.

[16] C.C. Hsieh and H.H. Lai, Capacity allocation with differentiated product demands under dual sourcing. Int. J. Prod. Econ. 193 (2017) $757-769$.

[17] B. Hu and Y. Feng, Optimization and coordination of supply chain with revenue sharing contracts and service requirement under supply and demand uncertainty. Int. J. Prod. Econ. 183 (2017) 185-193.

[18] S.H. Jung, Offshore versus onshore sourcing: quick response, random yield, and competition. Prod. Oper. Manag. 29 (2020) $750-766$

[19] M. Kelly and P. Siva, The Ripple Effect: How Manufacturing and Retail Executives View the Growing Challenge of Supply Chain Risk. Deloitte Consulting LLP (2013).

[20] R. Kerkkamp, W. Heuvel and A. Wagelmans, Two-echelon supply chain coordination under information asymmetry with multiple types. Omega 76 (2018) 137-159.

[21] D. Kostamis and I. Duenyas, Purchasing under asymmetric demand and cost information: When is more private information better? Oper. Res. 59 (2011) 914-928.

[22] X. Li, Y. Li and X. Cai, Remanufacturing and pricing decisions with random yield and random demand. Comput. Oper. Res. 54 (2015) 195-203.

[23] B. Niu, L. Chen and F. Xie, Production outsourcing for limited-edition luxury goods with the consideration of customers' origin preferences. Transp. Res. Part E: Logist. Transp. Rev. 140 (2020) 101975.

[24] I. Nosoohi and A.S. Nookabadi, Outsource planning with asymmetric supply cost information through a menu of option contracts. Int. Trans. Oper. Res. 26 (2019) 1422-1450.

[25] B.A. Pasternack, Optimal pricing and return policies for perishable commodities. Mark. Sci. 4 (1985) $166-176$.

[26] G. Pishchulov and K. Richter, Optimal contract design in the joint economic lot size problem with multi-dimensional asymmetric information. Eur. J. Oper. Res. 253 (2016) 711-733.

[27] B. Roy and B.C. Giri, A three-echelon supply chain model with price and two-level quality dependent demand. RAIRO-Oper. Res. 54 (2020) 37-52.

[28] D.A. Serel, A single-period stocking and pricing problem involving stochastic emergency supply. Int. J. Prod. Econ. 185 (2017) 180-195.

[29] S.Y. Tang and P. Kouvelis, Pay-back-revenue-sharing contract in coordinating supply chains with random yield. Prod. Oper. Manag. 23 (2014) 2089-2102.

[30] T. Taylor, Supply chain coordination under channel rebates with sales effort effects. Manage. Sci. 48 (2002) $992-1007$.

[31] M. Vosooghidizaji, A. Taghipour and B. Canel-Depitre, Supply chain coordination under information asymmetry: a review. Int. J. Prod. Res. 58 (2020) 1805-1834.

[32] Y. Wang, Y. Xiao and N. Yang, Improving reliability of a shared supplier with competition and spillovers. Eur. J. Oper. Res. 236 (2014) 499-510.

[33] Z.K. Weng, Channel coordination and quantity discounts. Manage. Sci. 41 (1995) 1509-1522.

[34] D. Wu, J. Chen, P. Li and R. Zhang, Contract coordination of dual channel reverse supply chain considering service level. J. Clean Prod. 260 (2020) 121071.

[35] M. Xu and Y. Lu, The effect of supply uncertainty in price-setting newsvendor models. Eur. J. Oper. Res. 227 (2013) $423-433$.

[36] W.L. Xue, T.M. Choi and L.J. Ma, Diversification strategy with random yield suppliers for a mean-variance risk-sensitive manufacturer. Transp. Res. Pt. e-Logist. Transp. Rev. 90 (2016) 90-107. 
[37] C. Yano and H. Lee, Lot sizing with random yields: a review. Oper. Res. 2 (1995) 311-333.

[38] F. Zabihi and M.K. Bafruei, Pricing and determining the optimal discount time of perishable goods with time and price dependent demand. RAIRO-Oper. Res. 51 (2017) 509-518.

[39] D. Zissis, G. Ioannou and A. Burnetas, Supply chain coordination under discrete information asymmetries and quantity discounts. Omega 53 (2015) 21-29.

[40] D. Zissis, G. Ioannou and A. Burnetas, Coordinating lot sizing decisions under bilateral information asymmetry. Prod. Oper. Manag. 29 (2020) 371-387.

\section{Subscribe to Open (S2O) A fair and sustainable open access model}

This journal is currently published in open access under a Subscribe-to-Open model (S2O). S2O is a transformative model that aims to move subscription journals to open access. Open access is the free, immediate, online availability of research articles combined with the rights to use these articles fully in the digital environment. We are thankful to our subscribers and sponsors for making it possible to publish this journal in open access, free of charge for authors.

\section{Please help to maintain this journal in open access!}

Check that your library subscribes to the journal, or make a personal donation to the $\mathrm{S} 2 \mathrm{O}$ programme, by contacting subscribers@edpsciences.org

More information, including a list of sponsors and a financial transparency report, available at: https://www. edpsciences.org/en/maths-s2o-programme 